\title{
O MUSEU DE ARTE E SUA DIMENSÃO EDUCATIVA: EM DEFESA DA CRIANÇA PEQUENA COMO PÚBLICO
}

\section{THE ART MUSEUM AND ITS EDUCATIONAL DIMENSION: IN DEFENSE OF THE YOUNG CHILD AS A PUBLIC}

\section{EL MUSEO DE ARTE Y SU DIMENSIÓN EDUCATIVA: EN DEFESA DEL NIÑO PEQUENO COMO PÚBLICO}

\author{
GABRE, Solange de Fátima \\ sogabre@gmail.com \\ Secretaria Municipal da Educação de Curitiba
}

\begin{abstract}
RESUMO Este artigo apresenta um recorte da tese "Para habitar o museu com o público infantil: uma proposta de formação colaborativa entre professoras da infância e profissionais do Museu Municipal de Arte de Curitiba"1. O objetivo centra-se em refletir sobre a educação museal e a sua relação com a infância. Seguindo uma linha qualitativa, a pesquisa bibliográfica e as observações de campo indicam que, a partir do entendimento de um museu educativo, reconhecer a presença da criança pequena em seu espaço se torna possível pela disponibilidade e investimento intelectual e sensível daqueles que estão diretamente envolvidos nesse trabalho.
\end{abstract}

Palavras-chave: Arte. Criança pequena. Educação. Museu.

ABSTRACT This article presents a clipping of the thesis "To inhabit the museum with the child public: a proposal of collaborative formation among preschool teachers and professionals of the Municipal Museum of Art of Curitiba". The objective is to reflect on museum education and its relationship with childhood. Following a qualitative line, the bibliographical research and the field observations indicate that from an understanding of an educational museum, to recognize the presence of the young child in its space is possible by the availability and intellectual and sensitive investment of those that are directly involved in this work.

Keywords: art. Education. Museum. Young child.

RESUMEN Este artículo presenta un recorte de la tesis "Para habitar el museo con el público infantil: una propuesta de formación colaborativa entre profesoras de la infancia y profesionales del Museo Municipal de Arte de Curitiba". El objetivo se centra en reflexionar sobre la educación museal y su relación con la infancia. Siguiendo una línea cualitativa, la investigación bibliográfica y las observaciones de campo indican que a partir del entendimiento de un museo educativo, reconocer la presencia del niño pequeño en su espacio, se hace posible por la disponibilidad intelectual y sensible de aquellos que están directamente involucrados en ese trabajo.

Palabras claves: Arte. Educación. Museo. Niño pequeno.

\footnotetext{
${ }^{1}$ A referida tese contou com o apoio do Programa de Doutorado Sanduíche no Exterior (PDSE), oferecido pela Coordenação de Aperfeiçoamento de Pessoal de Nível Superior (CAPES). Processo n. ${ }^{\circ}$ 99999.005195/2014-04.
} 


\section{INTRODUÇÃO}

Educação museal é um termo novo no contexto dos estudos de museus. Aqui será utilizado para definir as "iniciativas de educação desenvolvidas no âmbito de processos museais" (IBRAM, 2014, p. 13). Historicamente, envolve o trabalho realizado pelos setores educativos dos museus no que diz respeito às ações de aproximação dos públicos diversos à arte. Essas ações, de um modo geral, foram comumente pensadas tendo como ponto de partida o olhar do museu para o público. Contudo, tal visão está se alterando na atualidade, e um novo pensamento está sendo gerado. Com base em reflexões e ações de pesquisadores, educadores, artistas, enfim, de pessoas interessadas em arte e educação na sua relação com o museu, o entendimento passa a ser o de um museu educativo.

Nesse contexto, destaca-se que nos museus de artes brasileiros a educação começou a ganhar atenção no fim da década de 1930 aproximadamente (BENVENUTI, 2004). Todavia, mesmo depois de mais de 70 anos da abertura dos primeiros setores educativos, nem todos os museus brasileiros os possuem; nos casos positivos, a grande maioria permanece na invisibilidade, salvo algumas exceções. E mesmo que o conceito de museu ${ }^{2}$ definido pelo Conselho Internacional de Museus (em inglês: International Council of Museums - ICOM ${ }^{3}$ ), que rege muitos países, inclusive o Brasil, aborde sobre a função educativa como um de seus propósitos, existem ainda muitas dificuldades que acompanham essa função.

Este texto apresenta um breve recorte da tese 'Para habitar o museu com o público infantil: uma proposta de formação colaborativa entre professoras da infância e profissionais do Museu Municipal de Arte de Curitiba'(GABRE, 2016). Tem-se o objetivo de refletir sobre a educação museal a sua relação com o público escolar, sobretudo o público infantil. A pesquisa bibliográfica, pautada em autores que referenciam a área, e as observações realizadas em museus brasileiros e espanhóis indicam que, a partir do entendimento de um museu educativo, reconhecer a

\footnotetext{
${ }^{2}$ Lugar permanente que conserva, investiga, comunica, interpreta e expõe conjuntos e coleções de valor histórico, artístico, científico, técnico ou de qualquer outra natureza cultural com o objetivo de preservação, estudo, pesquisa, educação, contemplação e turismo. Está aberto ao público e a serviço da sociedade e de seu desenvolvimento.

${ }^{3}$ O ICOM, uma instituição internacional não governamental, foi criado em 1946 para representar os museus e seus profissionais em escala mundial que mantêm relações com a UNESCO.
} 
Atos de Pesquisa em Educação - ISSN 1809-0354

Blumenau, v.14, n.1, p.145-168, jan./abr. 2019

DOI: http://dx.doi.org/10.7867/1809-0354.2019v14n1p145-168

presença da criança pequena em seu espaço se torna possível pela disponibilidade e investimento intelectual e sensível daqueles que estão diretamente envolvidos nesse trabalho.

\section{EDUCAÇÃO MUSEAL E O PENSAMENTO CONTEMPORÂNEO}

No contexto brasileiro é comum encontrarmos a educação museal pensada em termos de democratizar o acesso à arte, conforme descrito no artigo 29 da Lei n. ${ }^{\circ}$ 11.094, de 14 de janeiro de 2009: "Os museus deverão promover ações educativas, fundamentadas no respeito à diversidade cultural e na participação comunitária, contribuindo para ampliar o acesso da sociedade às manifestações culturais [...]" (BRASIL, 2009). Salienta-se que a promoção do acesso perpassa pela questão da qualidade desse acesso, no que diz respeito à ampliação cultural e social das pessoas, por meio de iniciativas de ações educativas com a participação efetiva dos diferentes públicos.

Nesse sentido, a pesquisa 'Encontros com o futuro: prospecções do campo museal brasileiro no início do século XXl', realizada em parceria entre o Instituto Brasileiro de Museus (IBRAN) e o Instituto de Pesquisa Econômica Aplicada (IPEA), traz um alento para a questão. O estudo procurou "apontar tendências do campo museal brasileiro a respeito de temas variados que permitam inferir possibilidades de atuação sob diferentes cenários, num horizonte de dez anos" (SILVA et al., 2014). A nova tendência dos museus e o seu papel educativo são assinalados tendo como referência as considerações apontadas em um documento formalizado no encontro 'Mesa-Redonda de Santiago do Chile', realizado em 1972.

\footnotetext{
De repositórios de antiguidades, consideradas testemunho de uma época, de grupos sociais valorizados ou de fatos notáveis, os museus passam a desempenhar um papel pedagógico, popularizando acervos e educando. Transformaram-se em espaços vivos, ao contrário da imagem de cemitério de objetos. As instituições museológicas são ativas, múltiplas, diversas e é possível torná-las ainda mais dinâmicas (SILVA et al., 2014, p. 82).
}

Com um entendimento de um museu mais dinâmico e que vislumbra novas possibilidades de atuação, o público passa a ser visto com maior cuidado, interesse e potencial. Tal discussão vem se concretizando mesmo que em ações esporádicas. Um exemplo no cenário nacional, apesar de ser num contexto de exposição 
temporária, mas que repercute ainda hoje em nível internacional, sendo tomado como uma referência, foi a criação do cargo de curador pedagógico, que assumiu a

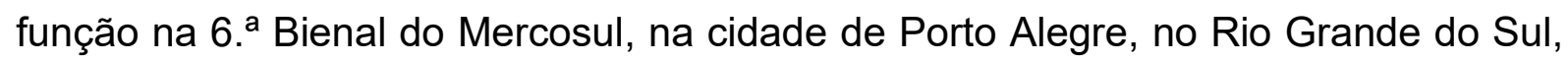
no ano de 2007. O evento que se tornou conhecido como a 'Bienal Pedagógica' teve o artista, pedagogo e curador Luis Camnitzer designado para tal função. Ao assumila, Camnitzer rompeu com o formato tradicional das bienais anteriores que, em suas palavras,

[...] cumpria-se [o formato das funções assumidas nas bienais] com o propósito considerado mais importante, o de dar um cenário aos curadores e às obras. Posteriormente, acrescentava-se um programa de extensão cultural com a intenção de ampliar e educar o público o máximo possível em termos da apreciação da arte (CAMNITZER, 2009, p. 14).

A intenção, ao inverter a ordem estabelecida que é bastante comum nos museus, foi começar um projeto pedagógico integrado no todo da bienal e possibilitar uma maior interatividade com o público. Nesse sentido, Camnitzer (2009, p. 13) afirma que a "equipe curatorial redesenhou a estrutura da Bienal para destacar a relação entre o artista e o público, para envolver o visitante no processo criativo do artista". Assim, o curador pedagógico "atua como um embaixador do público e observa o evento com os olhos do visitante" (CAMNITZER, 2011, p. 15). O desenvolvimento desse trabalho baseou-se em um projeto bastante sólido de pesquisa, formação e encontros prévios que envolveu os membros de todos os níveis participantes da bienal. Como consequência teve-se o estabelecimento de uma nova relação com o público visitante, que deixou de ser passivo e passou a atuar criativamente.

Esse novo pensamento seguramente afeta instituições culturais e museus sobre seu papel educativo, pois é necessário que eles se abram para o processo de estabelecer relações, tão importantes na atualidade. Pensar no museu como um espaço educativo vai além de organizar uma exposição de forma didática e mais compreensível aos diferentes públicos; inclui o pensamento de um museu mais integrado, que exerce um trabalho colaborativo e horizontal desde dentro. Sem dúvida, trata-se de um dos grandes desafios na contemporaneidade.

No entanto, a questão que se coloca em pauta é: De que maneira interferir na ordem preestabelecida e hierarquizada dentro dos museus efetivando sua dimensão educativa? Como evidencia Coca (2014), se o museu quer desenvolver uma política 
educativa de qualidade, a educação deve ser assumida de forma global e os profissionais da área educativa também precisam sejam considerados nas tomadas de decisões discursivas.

Ao reivindicar um novo olhar para o espaço do museu e ao revelar seu papel fundamentalmente educativo, Camnitzer, em seu trabalho como artista, também ratifica esse aforismo em sua obra El Museu es una Escuela: el artista aprende a comunicarse, el publico aprende a hacer conecxiones.

A instalação, exibida pela primeira vez em 2013 no Museu de Arte Latinoamericana de Buenos Aires (MALBA), depois em várias outras instituições em Nova York, no Chile e Madrid, problematiza a redefinição do museu como um espaço educativo e busca efetivar as novas relações de colaboração entre instituição, artista e visitante. Camnitzer explica que o projeto visa

[ ] forzar al museo que acepta a hacerlo a que establezca un contrato de
servicios con el público sobre cómo se va a comportar de allí en adelante.
Implica que se dedicará a hacer muestras dentro de un espíritu educativo y
no funcionar meramente como un depósito de obras coleccionadas en honor
de los dueños y los consejos de directores. Se trata justamente de minimizar
la huella del ego y acentuar la función pedagógica. Es por eso que insisto en
que la obra pase a ser institucional y no como expresión de mi arte, para
que el público pueda exigir una rendición de cuentas si percibe que la
institución está traicionando el espíritu de la frase. Es por eso que la
tipografía es la que normalmente utiliza el museo, el diseño está hecho por
el equipo de diseño de la institución y existe un compromiso de publicar una
postal "oficial". Es obligar a las instituciones a que dejen de funcionar como
mausoleos erigidos en honor de algún individuo o individuos, o de una clase
social, y entrar en un contrato social que redistribuya el poder (FUNDACIÓN
MALBA, 2015).

Nessa perspectiva, é imprescindível compreender que mudanças relacionadas às práticas museais, as quais envolvem tanto curadoria quanto educação, são urgentes. Diante desses apontamentos, autores como Efland, Freedman e Stuhr (2003), Mörsch (2011), Acaso (2011), entre outros, fundamentam a necessidade de um giro educativo no campo da arte.

Carmen Mörsch (2015), responsável pela área educativa da exposição de arte Documenta 12, esclarece que o termo giro educativo surgiu com o crescente interesse do campo curatorial e artístico pelo pedagógico, em particular pelas pedagogias emancipatórias que encontram fundamentos principalmente em autores como Paulo Freire e Jacques Rancière. Nas palavras de Mörsch (2011, p.6), esse giro educativo tem a ver com 
[...] un cambio de perspectiva del comisariado y en la producción artística hacia una busqueda por conceptos de educación que reaccionan a la época atual, que pongan resistencia, que partan de la necesidad de individuos y colectivos y de esa manera sean emancipadores. [...] El cambio de perspectivas postula una vez más la relevancia social del arte y del trabajo comisarial, y de esa manera les outorga sentido.

Tal trabalho exige bastante esforço, dedicação e interesse em transformar a realidade, como podemos observar na experiência que é desenvolvida desde o ano de 2007 no Museo de Arte Contemporáneo Español Patio Herreriano, em Valladolid (Espanha), por meio do projeto Sala Cero. O projeto, desenvolvido pelo Departamento de Investigação e Educação do museu, surgiu de reflexões geradas no interior do próprio grupo de trabalho sobre educação e prática artística.

\footnotetext{
Las iniciativas generadas por el Área de Educación siempre se enmarcaban en las exposiciones temporales o en el montaje de la colección, pero nunca tenían la posibilidad de participar en el diseño de las mismas. En este sentido, nuestros programas únicamente podían reafirmar el discurso institucional o bien cuestionarlo, pero en ningún caso participaban en la toma de decisiones expositivas de la institución (COCA; PÉRES, 2011, p. 16).
}

Assim, o interesse desse trabalho centrou-se em resolver problemas quanto ao papel secundário dos educadores do museu ante os demais profissionais e "aplicar desde un ámbito estrictamente artístico un programa educativo capaz de dar voz a los diferentes públicos" (COCA, 2009, p. 183). O movimento possibilitou que uma sala do museu fosse disponibilizada para o desenvolvimento do trabalho, denominada Sala Cero. De acordo com Coca (2014, p. 195), o nome Sala Cero, num primeiro momento, fazia referência à primeira exposição realizada, porém com o passar do tempo se converteu em "en una singular referencia a una hipotética 'zona cero' donde se sitúan aquellas iniciativas de comisariado educativo que pretenden romper con las políticas expositivas tradicionales de la institución".

Depois da primeira exposição, chamada Montaje Educativo, outras foram realizadas: Algo tendrás que decir, Rompiendo Moldes, La Mirada Observada, Para Raro/Para Normal. Segundo Coca (2014), depois da segunda montagem, o projeto expositivo Sala Cero já havia se consolidado dentro do museu mais do que uma sala expositiva, transformando-se em um laboratório para refletir e repensar o papel da curadoria a partir do contexto educativo.

Outra experiência bastante significativa e dentro do contexto brasileiro, a qual 
vem sendo disseminada em alguns eventos da área, é o trabalho educativo que acontece no Museu de Arte do Rio (MAR).

O MAR, apesar de seu pouco tempo de experiência, pois foi inaugurado no mês de março do ano de 2013, trabalha numa perspectiva de um museu educativo e integrado à comunidade.

Janaina Melo (2015), responsável pela área educativa do MAR, em palestra proferida no Museu de Arte de São Paulo (MASP) falou que a estreita relação que o museu estabelece com a comunidade local é imprescindível para o trabalho educativo que ele promove. Como uma das missões do museu é inscrever a arte no ensino público, desenvolve por meio do projeto Escola do Olhar um trabalho ${ }^{4}$ em que se discutem arte, cultura da imagem, educação e práticas curatoriais.

O museu é um espaço de educação, afirma Janaina, e mesmo que as questões que envolvem a educação e a curadoria estejam sempre num terreno de disputa, no MAR a agenda de educação se constrói com base nas mesmas questões, perguntas e debates que a curadoria tem no momento de pensar uma exposição. Portanto, a educação não é um apoio à curadoria nem uma reprodução do discurso curatorial.

Os exemplos citados mostram-se como atos que preconizam a urgência de se gerar uma política dentro das próprias instituições museais e em colaboração com a sociedade, no sentido de possibilitar um debate para que ações possam ser empreendidas e novas narrativas criadas.

\section{EDUCAÇÃO MUSEAL E O PÚBLICO ESCOLAR: NOVAS RELAÇÕES}

Ao se falar em educação museal é importante considerar a expressiva importância que a escola assume nesse âmbito. É cada vez maior o aumento de oferta e de iniciativas educativas dos museus pensando no público escolar e, por outro lado, há uma crescente procura das escolas pelos serviços oferecidos pelo museu.

De acordo com Barbosa (2009, p. 17), o público mais numeroso dos museus é sem dúvida o escolar $\mathrm{e}$ isso se deve ao fato do acontecimento das

\footnotetext{
${ }^{4}$ Feito em parceria e em colaboração com a Secretaria Municipal do Rio de Janeiro, universidades e outras secretarias e instituições.
} 
megaexposições, por volta da década de 1990 no Brasil, e à constatação de que a participação desse público nesses eventos "infla as estatísticas e ajuda a mostrar grande número de visitantes aos patrocinadores". Essa afirmação foi ratificada em uma pesquisa, coordenada por Magaly Cabral (2006), sobre a avaliação das práticas educativas nos museus brasileiros. Dos 192 museus brasileiros participantes, 82\% declararam desenvolver atividades educativas; quanto ao tipo de prática que oferecem, o destaque foi para as ações voltadas às escolas.

Para além do papel quantitativo que é atribuído às escolas, outra responsabilidade refere-se à formação da sociedade para o consumo ${ }^{5}$ cultural, conforme apontado em pesquisa realizada pelo Ministério da Cultura (MinC) e o Instituto de Pesquisa Econômica Aplicada (Ipea), sob coordenação do professor doutor Frederico Augusto Barbosa da Silva. Nela se evidencia que, em levantamento feito entre 2002 e 2006, cerca de $70 \%$ dos brasileiros nunca tinham ido a um museu. A reflexão desenvolvida por Silva (2007, p. 12) é de que a questão do consumo cultural está diretamente ligada aos direitos e à cidadania e, consequentemente, passa pela escolarização formal, pois esta faculta "[...] às pessoas o acesso ao patrimônio simbólico das sociedades" no que se refere à capacidade de "[...] dotar as pessoas dos recursos que permitem a apropriação sistemática e universal dos recursos culturais".

Entendemos que a escola detém grande potencial que lhe permite contribuir na transformação da sociedade para a apropriação do patrimônio cultural do país. No entanto, é apropriado considerar que hoje os museus, entendidos na sua dimensão educativa, ainda que dentro de um contexto de educação não escolar, assumem também um enorme papel. Para tanto, vale ressaltar que um dos caminhos para que o acesso aos bens culturais seja ativado, com a qualidade necessária, no sentido de gerar o sentimento de pertença nas pessoas, é o trabalho compartilhado entre ambas as instituições, escolas e museus. Desse modo, podemos inferir com Ricard Huerta que

\footnotetext{
${ }^{5}$ Segundo Silva (2007, p. 11), "o consumo é um conjunto de processos socioculturais nos quais as pessoas se apropriam e usam produtos e serviços de forma a dizer algo sobre si mesmas, a sociedade, os grupos e as localidades em que vivem. Portanto, o consumo diz respeito à totalidade das interações sociais, desde a distinção entre grupos, até o estado do sistema educacional e das inovações tecnológicas. Consumir é participar dos cenários da vida social, de suas disputas e significado. A escassez de bens impõe certa lógica: a de que alguns se apropriem dos bens e outros não, em um processo que permite a distinção e união, o reconhecimento do valor dos bens ou sua desvalorização, assim como daqueles que os consomem".
} 
los museos necesitan a las escuelas, y vice-versa. No sólo se necesitan mutuamente, sino que también adquieren mayor identidad al funcionar conjuntamente, al combinar sus fuerzas, al generar un territorio común. [...] Pero tanto los museos como las escuelas se fortalecen al conectar sus especificidades, para evolucionar y para adecuarse a la realidad social (HUERTA, 2010, p. 57).

Entre escolas e museus, historicamente, há "uma relação de poder implícita que cria muitas barreiras e silêncios" (ALDEROQUI, 2015) e, mesmo sem generalizar a questão, há muitos conflitos e descompassos.

Huerta (2010) trata da questão do professor no museu e evidencia a situação habitual de sua invisibilidade. Para ele, por meio da escuta dos professores é possível compreender melhor a realidade educativa das escolas e também valorizar os profissionais que se interessam pela arte. Huerta $(2010$, p. 56) defende o professor "como sujeto frente a la tan habitual estampa del maestro como objeto".

A visão do professor como objeto pode ser observada em muitos casos durante a visita ao museu com seus estudantes. Tal constatação é notada tanto na postura de alguns professores quanto na atitude dos mediadores quando os ignoram durante as propostas educativas. Nesse sentido, entender o professor como sujeito é, segundo Tardif (2002), considerá-lo na sua subjetividade, ou seja, como detentor de saberes específicos mobilizados na ação cotidiana.

Alderoqui (2015) reforça essa premissa ao abordar em palestra proferida no Museu Thyssen-Bornemisza sobre a necessidade de construir novas relações e imaginários entre escola e museu tendo como princípio uma ideia de colaboração. A autora enfatiza que, uma vez que os imaginários são construções coletivas, o entendimento de museu, construído ao longo de sua existência, foi o de um lugar de coisas velhas e, por outro lado, a escola é vista como resistente às mudanças e focada num currículo fechado. Todavia, chegou a hora de mudanças, e a mudança desses imaginários, para o estabelecimento de novas relações entre museus e escolas, pode acontecer na disponibilidade de diálogo, balizado em conciliar as transformações de ambas as instituições num trabalho colaborativo.

\section{EDUCAÇÃO MUSEAL E O PÚBLICO INFANTIL: SABERES NECESSÁRIOS}

Ao tratar do público escolar no museu, é comum a associação com as etapas 
do ensino fundamental e médio, pois historicamente essas fases foram e são as mais contempladas nas programações dos museus. No entanto, o público escolar corresponde às três etapas da educação básica, as quais, de acordo com a Lei n. ${ }^{0}$ 9.394 (Lei de Diretrizes e Bases da Educação Nacional - BRASIL, 1996) compreendem a educação infantil, o ensino fundamental e o ensino médio.

A presença do público infantil no museu é uma situação presente, embora seja algo novo no contexto brasileiro. Cada vez mais tanto as instituições de educação infantil como as famílias procuram o museu como uma possibilidade de encontro e aprendizagem para além do contexto familiar e dos muros escolares. Por outro lado, aos poucos, as equipes educativas dos museus se mobilizam e lançam algumas propostas educativas para contemplar a referida faixa etária. Prova disso é o projeto 'Bebês no Museu', desenvolvido pela Área de Ação Educativa do Museu Lasar Segall, que foi ganhador do prêmio Melhores Práticas, concedido pelo CECA/ICOM, e aprovado para participar da Conferência Anual em Alexandria, em junho de 2014.

Além dessa experiência, o Museu Lasar Segall, em parceria com a instituição Casa das Rosas, realizou no ano de 2014 o primeiro Seminário 'Bebês no Museu: experiências', juntamente a um curso, no mês de agosto do mesmo ano. O seminário possibilitou que especialistas abordassem a temática e que os profissionais que estão desenvolvendo experiências na área pudessem relatá-las. A iniciativa foi o início de um diálogo para um pensamento fundamentado sobre a presença da criança pequena nos museus, bem como um incentivo para a efetivação do seu acesso por intermédio de ações concretas.

Uma experiência internacional, também com ênfase no bebê e sua família, é o evento May Baby, desenvolvido no WIELS, Centro de Arte Contemporânea de Bruxelas, já em sua quarta edição. Realizado nos fins de semana, May Baby é um convite aos pais de crianças de seis meses a dois anos de idade para participarem de propostas interativas, experimentações artísticas e sensoriais.

Conectado a esse mesmo pensamento sobre as crianças pequenas e suas famílias no espaço do museu, o Museu do Prado, na cidade de Madrid na Espanha, realiza o Espetáculo-taller denominado Pintor de Nubes. O trabalho, destinado a bebês de zero a três anos de idade, baseia-se nas obras do artista El Greco. Consiste num espetáculo para que pais e filhos entrem em contato com as obras do 
artista de forma lúdica e atraente. Depois de assistir ao espetáculo repleto de encantamento, luzes, formas, texturas e cores, a família é convidada a conhecer as obras do artista expostas no museu.

E quando a visita das crianças pequenas é efetivada pela escola? Como as crianças e os professores são recebidos? Que ações são desenvolvidas? Tais questionamentos são trazidos por Lima (2009, p. 159) ao lançar o projeto 'Pequenos no Museu', em 2006, como parte do projeto educativo do Museu de Arte Moderna Aloisio Magalhães (MAMAM), em Recife: um dos maiores problemas encontrados foi "trabalhar a formação em serviço dos educadores do museu para que pudessem escolher, em visita agendada, as crianças de 2 a 6 anos e assim repensar a própria prática $[\ldots] "$.

Essas problematizações são também apontadas por Carvalho em sua pesquisa de doutorado realizada no Centro Cultural do Banco do Brasil no Rio de Janeiro (CCBB). A autora evidencia, por meio da fala das mediadoras, as resistências quanto ao trabalho com o público infantil:

[...] "Eu não sei o que fazer com as crianças pequenas. Não gosto mesmo. Acho que fica escrito na minha testa. E não sei se tem muito a ver a vinda delas". "O que se pode fazer com os pequeninos nessas exposições? Eles não podem entender nada disso. Nem entendem o que eu falo!". "Criança menorzinha, assim de quatro, cinco anos, ninguém merece!" (CARVALHO, 2013, p. 304).

As dificuldades apresentadas revelam inquietações muito pertinentes, e destacamos algumas delas, implícitas no relato: Qual a motivação da resistência de alguns museus e de mediadores em receber o público infantil? Toda exposição pode ser visitada com a criança pequena? Há um tipo de arte específica para criança? Como é a comunicação entre adultos e crianças pequenas? Como se dão os processos educativos na relação entre a escola infantil e o museu?

Com base nessas reflexões, é oportuno esclarecer que pensar a criança pequena no museu e realizar ações com ela e com os adultos que a acompanham pode se dar de maneira muito prazerosa. No entanto, há a necessidade da apropriação de alguns saberes para a compreensão do todo que envolve esse trabalho; o principal deles é entender qual o conceito de criança na atualidade. Para tanto, é importante a distinção entre os conceitos de criança e infância. Crianças existem desde sempre, pois se refere ao período biológico vivido por todo e qualquer 
ser humano. No entanto, a categoria infância foi algo construído nos contextos sociais e teve início nos séculos XVII e XVIII. Tal categoria é marcada pela trajetória singular de cada criança a partir das relações que estabelece em seu meio, com outras crianças, com adultos, com as imagens, com os meios de comunicação, entre outros elementos. Portanto, não podemos generalizar a infância; devemos compreendê-la na sua pluralidade e transformações constantes.

Da ausência desse entendimento de que a infância é algo construído socialmente e de formas distintas, em cada época e contexto, decorrem os equívocos, e a noção naturalizada de uma universalidade da infância se instaura. Isso pode gerar insegurança, bem como a negação do atendimento a esse público no museu, ou ainda a projeção de uma imagem de criança como aquela construída na modernidade, como

[...] incompetente, totalmente desapossada do poder, abrigada à submissão e obediente aos mais velhos, incapaz de produção cultural autônoma, reprodutora cultural em processo de aprendizagem, objeto do cuidado e da proteção de quem exerce o poder paternal, personagem ausente ou passiva dos lugares da decisão coletiva [...] (SARMENTO, 2013, p. 37).

Como esse não é o espelho da criança contemporânea, surge a enorme dificuldade em lidar com ela nos diferentes contextos, e não seria diferente nos museus, tornando-se um público muitas vezes indesejado.

Hoje, a visão de criança e infância que se tem, e que se procura desenvolver, nas diferentes esferas da sociedade, é a de um ser social capaz de construir conhecimento, com cultura própria, como nos alertam Sarmento (2004) e Dahlberg, Moss e Pence (2003) e também tantos outros pesquisadores. Eles afiançam que a criança existe para além do contexto familiar e se relaciona ativamente na sociedade onde está inserida. Por isso, é fundamental compreendê-la como cidadã e, como tal, possuidora de direitos e de cultura própria, que precisam ser respeitados.

Todavia, a efetivação do direito da criança pequena em visitar museus e espaços culturais significa mais do que aceitá-la, haja vista ser necessário saber se as estratégias desenvolvidas com as crianças pequenas levam em consideração as suas especificidades. Sarmento (2004) esclarece que podemos melhor compreender as crianças por meio de quatro eixos: ludicidade, interatividade, fantasia do real e reiteração. 
A 'ludicidade' talvez seja o eixo mais visível nas crianças, mesmo não sendo exclusivo delas. Elas adoram brincar e é por essa via que desenvolvem sua aprendizagem. Abad e Velasco (2011, p. 145) enfatizam que a brincadeira "puede ser la mejor estrategia para obtener una intensa experiencia espacial, como contexto significativo, si se ofrecen las condiciones necesarias". Com base nessa reflexão, interrogamos: $\mathrm{E}$ no museu, oferece-se às crianças a possibilidade de brincar? Entender o museu como um lugar onde a brincadeira possa acontecer é permitir à criança

[...] (re)descobrir o museu sob um outro ângulo, entrando por uma outra porta, agindo sob determinada luz, determinado som, brincando com seu próprio corpo no espaço. Sob este ponto de vista, o ritmo de jogo dos protagonistas pode também ser encontrado; cada visita torna-se, então, singular (ABAD; CHAVEPEYER, 2014, p. 16).

A possibilidade de ocupar o espaço do museu por meio da brincadeira e do próprio corpo leva-nos ao segundo eixo sobre as culturas da infância, a 'interatividade'. Ao entender que o mundo da criança não é homogêneo, mas, ao contrário, ela se relaciona com as pessoas nos mais diversos contextos, para além da família, seja na escola, na rua, num parque, no museu, e que nessa relação "vai apreendendo valores e estratégias que contribuem para sua formação e sua identidade pessoal e social" (SARMENTO, 2004, p. 23), compreende-se que pela 'interatividade' a criança se apropria, reinventa e reproduz o mundo que a rodeia.

Carvalho evidencia essa interatividade da criança no espaço do museu, que passa despercebida pelos mediadores. Conta que, durante as observações no museu onde desenvolveu sua pesquisa, percebeu que

[...] a participação das crianças pequenas era, em geral, muito ativa: indagavam sobre obras não exploradas pelos monitores, questionavam todo o tempo, interrompendo quando não entendiam, tinham dúvidas ou queriam fazer algum outro comentário. [...] as surpresas se apresentavam tanto aos monitores quanto às crianças. Muitas vezes as indagações por elas trazidas se desviavam da estratégia planejada [...] diante de uma obra exposta [...]; outros desde o início adotavam uma linguagem "infantilizada" para a visita, o que em alguns momentos dificultava a interação (CARVALHO, 2013, p. 305).

Essa ação das crianças mostra suas potencialidades e a capacidade em construir conhecimento junto aos adultos, a curiosidade e sede de respostas ao 
desconhecido. E como assinala Leite (2005, p. 51), a criança "vive a realidade, transforma-a e é por ela transformada. Para tal, é necessário que possa tocar, questionar, dialogar aquilo que vê". No entanto, se os adultos não compreenderem isso e se não estiverem atentos aos saberes das crianças, situações muito ricas trazidas por elas não serão aproveitadas no espaço do museu.

Dornelles (2013, p. 20) aponta um exemplo claro da capacidade e da potencialidade de entendimento das crianças, ao questioná-las sobre o que aprenderam do mediador durante a visita, quando obteve algumas respostas, como a de Ryan: "Nada! Eu já sabia tudo, não precisava ter alguém explicando!", ou a de João: "Fica chato alguém explicando".

Diante dessas reflexões, fica evidenciado que pensar a interatividade das crianças nos espaços dos museus se torna extremamente necessário para que a experiência seja significativa.

Outro eixo que estrutura a infância é a 'fantasia do real'. Nas palavras de Sarmento (2004, p. 26), o faz de conta "faz parte da construção pela criança da sua visão de mundo e da atribuição do significado às coisas" e é na relação que a criança cria entre o real e o imaginário que o seu mundo se constrói. Carvalho (2013, p. 306) mais uma vez pode ajudar a exemplificar como isso pode funcionar no museu, ao notar durante a observação que fazia em uma visita que "frases simples como 'lá dentro eu vou te contar um segredo' eram suficientes para que a curiosidade fosse despertada [...]".

O último eixo, a 'reiteração', está relacionado à incrível capacidade da criança em criar e recriar seu mundo num processo contínuo. E nesse processo, o tempo da criança é "continuamente reinvestido de novas possibilidades, um tempo sem medida, capaz de ser sempre reiniciado e repetido" (SARMENTO, 2004, p. 28).

A ausência da compreensão dos elementos que constituem a infância pode fazer com que os mediadores se sintam inseguros com a presença da criança pequena no museu, pois a visão comumente construída sobre elas, como incapazes, se revela nas atitudes e vozes, como foi possível perceber nos exemplos citados.

Portanto, além do entendimento do conceito de criança, das diferentes infâncias e das estruturas que a formam, faz-se imprescindível aprofundar um pouco mais esses saberes na relação que estabelecemos com as crianças no espaço do museu, para que tal ação seja a mais significativa possível para todos. 
Atos de Pesquisa em Educação - ISSN 1809-0354

Blumenau, v.14, n.1, p.145-168, jan./abr. 2019

DOI: http://dx.doi.org/10.7867/1809-0354.2019v14n1p145-168

Há uma importante referência, publicada em julho de 2013, que nos ajuda a encontrar caminhos que esclarecem algumas das interrogações levantadas anteriormente: trata-se do Manifesto: Museos de arte amigos de los niños pequeños. O documento faz uma crítica aos grandes museus da Europa, onde normalmente se encontram muitas obras com representações de crianças pequenas feitas por diferentes artistas consagrados. Essas obras podem ser contempladas a qualquer momento pelos visitantes, entretanto as crianças pequenas nem sempre são bemvindas, e as motivações são várias. Conforme Fallon e Chavepeyer (2013, p. 3),

[...] puede que se pongam a correr por todas partes, a gritar, a reir, a llorar, a babear, a tirarse por el suelo, puede que necesiten comer con urgência, o incluso, que encuentren más interesante un extintor que un cuadro. Ellos no dominan los códigos de conduta habituales en esos lugares.

Sobre essas características tão comuns em crianças pequenas e que, no entanto, podem conturbar o espaço do museu e incomodar os adultos, as autoras evidenciam que já se pode observar que em alguns lugares pensar a presença da criança pequena e crer na sua capacidade e potencialidade é possível. Estas mesmas autoras (2013, p. 3), indicam que o documento foi produzido numa tentativa de "sensibilizar a los responsables políticos para que se comprometan a desarrollar una verdadeira gestión cultural y artística dirigida al setor de la primera infancia".

O primeiro destaque do documento trata de questionar 'o motivo pelo qual levar um bebê ou uma criança pequena a um museu'. Além de abordar a questão do direito da criança em participar plenamente da vida cultural e artística da sociedade, assinalado no artigo 31 da Convenção dos Direitos das Crianças, podemos inferir com as autoras que visitar um museu com os pequenos

no se trata de "consumir arte" de la manera más precoz posible, sino de explorar el sentido que puede adoptar una visita al museo con los más pequeños. Una visita que parecería un paseo, es decir, una vuelta "sin utilidad",!pero muy útil! Una vuelta poesía. Una vuelta sueño. Una vuelta para nada... nada más que por el placer de descubrir juntos el mundo, de dejarse sorprender por el encuentro inesperada con un cuadro, de jugar con los movimientos de una escultura, de alegrarse al reconocer a un personaje o a una escena familiar en una obra... (FALLON; CHAVEPEYER, 2013, p. 4).

Na maioria dos casos, as crianças da educação infantil que visitam o museu o fazem pela primeira vez com a escola. Portanto, a responsabilidade que se instaura 
Atos de Pesquisa em Educação - ISSN 1809-0354

Blumenau, v.14, n.1, p.145-168, jan./abr. 2019

DOI: http://dx.doi.org/10.7867/1809-0354.2019v14n1p145-168

nesse encontro deveria ser compartilhada entre escola, família e museu e entendida como um momento poético, de encantamento, de assombro, descobertas e de alegria, como citam as autoras. E nesse encontro são muitos os aspectos a serem considerados. Um deles é o de 'que a percepção do mundo para as crianças pequenas se dá pelos sentidos', ou seja, além da "extraordinária agudeza sensorial, el niño pequeño es también un ser motor: el movimiento es vida [...]" (FALLON; CHAVEPEYER, 2013, p.5). Então, não é possível querer mantê-las sentadas e quietas por muito tempo. O museu deve compreender e adequar-se a essa demanda em suas estratégias de ação.

Outro aspecto a ser valorizado é a 'capacidade de interpretação das crianças' e a possibilidade da experiência sensível. Nas palavras de Fallon e Chavepeyer (2013, p. 8),

\begin{abstract}
las emociones estéticas no son privativas de una élite sabia y cultivada, sino que forman parte de la naturaleza humana [...] Los artistas ofrecen formas y lenguajes para dialogar con nosotros mismos. Al interpretar las obras para hacerlas nuestras, las recreamos. Siguen vivas gracias a nuestra mirada. El encanto de estos encuentros nos produce deseos de ir más lejos y nos volvemos curiosos, menos tímidos, con gustos más variados. Entrar en los museos nos da la oportunidad de conocer obra que verdaderamente nos conmueven y de formar poco a poco nuestro "museo interior". Los niños pequeños, curiosos por naturaleza, están dispuestos a descubrir todas las formas de los lenguajes artísticos. Necesitan ser alimentados con representaciones múltiples para poner palavras e imágenes a suas experiencias.
\end{abstract}

Dessa perspectiva, compreendemos que escutar o que dizem as crianças e valorizar suas ideias e impressões acerca daquilo que veem e se relacionam é fundamental.

Com base em tal reflexão outro destaque a se fazer é sobre o que mostrar às crianças no museu de arte. 'Existe uma arte própria para os pequenos?' A questão é problematizada na Convenção dos Direitos das Crianças, e enfatizamos ser necessária a compreensão de que a resposta a essa indagação é bastante complexa, pois, ao mesmo tempo em que dizemos sim, também dizemos não. Conforme Fallon e Chavepeyer (2013), podemos dizer não porque uma criança pequena não é sinônimo de obra pequena e, por menor que seja, toda pessoa é sensível ao contato com a obra de arte original. Contudo, também respondemos sim porque, apesar de acreditar na capacidade e competência das crianças, elas estão em processo de desenvolvimento e, portanto, são fundamentais o respeito ao seu 
ritmo de descobertas e a confiança em seu modo singular de apreciar as obras de arte. No encontro com a obra de arte no museu, há um mundo de possibilidades e descobertas, logo, "no es necesario agobiar al niño con informaciones y emociones con las que, debido a su falta de madurez psíquica, no puede hacer nada, más que darse la vuelta o quedarse pasmado" (FALLON; CHAVEPEYER, 2013, p. 9).

Essa última reflexão nos leva a problematizar uma prática bastante corriqueira desenvolvida nos museus, principalmente nas visitas de escolares. 'É necessário oferecer uma oficina ao final da visita?' Situação bastante comum nas ações feitas com as crianças que visitam o museu. Nas oficinas, as crianças são convidadas a realizar propostas práticas, como a que foi divulgada no site de um museu da região sul do Brasil, em comemoração ao seu aniversário.

Após conhecerem um pouco sobre escultura, em especial a escultura que representava um jacaré, as crianças de uma escola de educação infantil participaram da "Oficina da Escultura". Elas construíram um jacaré com material descartado, para reforçar a importância da reciclagem para o meio ambiente, e ao final puderam levar as esculturas para casa como lembrança da visita. O resultado dessa prática revela uma concepção de ensino da arte que vai à contramão do que se espera da arte hoje, seja no museu ou na sala de aula, e da própria noção de criança e sua relação com os saberes e fazeres da arte. O foco na atividade proposta, no exemplo dado, reforça a preocupação do adulto com o produto bem acabado, 'bonito', esquecendo-se de que o mais importante para a criança, sobretudo para a criança pequena, é o processo, a experiência vivida. Em propostas assim

[...] as crianças aprendem que seu limite para imaginar está confinado a retângulos e recortes do mundo feito pelos adultos. Aprendem que os outros são detentores dos saberes. Aprendem que precisam de modelos para seguir as linhas predeterminadas de suas vidas. [...] Aprendem a respeitar modelos e posturas quando têm minutos para executar um trabalhinho (CUNHA, 2012, p. 26).

Ações que desencadeiam nas crianças essa submissão estão presentes tanto nas escolas quanto no museu, portanto, é necessário repensá-las. Se as propostas de mediação fossem pensadas de modo a favorecer a construção do olhar por meio do que veem no museu, suas leituras de mundo poderiam ser ampliadas. Nesse sentido, é importante considerar a possibilidade de pensar em propostas que 
permitam às crianças

[...] actuar acerca de las obras durante la visita y permitir así el descubrimiento, la percepción y la comprensión de estas será sin duda más provechoso. Podrá relacionar sus emociones, su pensamiento y las experiencias, los descubrimientos que le ofrece el museo (FALLON; CHAVEPEYER, 2013, p. 15).

Entendemos que, para a criança pequena, a aproximação e o conhecimento da arte "não vai [vão] se dar [...] na forma de adestramento manual, mas sim com intervenções pedagógicas que desvelem e ampliem os saberes individuais e coletivos [...]" (CUNHA, 2012, p. 27).

Acaso (2009) afirma que, pelo fato de não se considerar o ensino da arte uma área de estudo vinculada à parte intelectual, mas ligada ao manual, o termo manualidades é o que melhor define a arte. A esse respeito a autora diz:

\begin{abstract}
Las manualidades, como su propio nombre indica, se nos aparecen como un auténtico pasatiempo en el que se realizan cosas con las manos, por lo que los únicos procesos que se desarrollan en la ejecución de dichas cosas son aquellos enfocados en la producción, dejando de lado el análisis. Estas cosas han de cumplir una premisa fundamental: han de ser bellas, gustar, ser bonitas, ser ornamentales, decorar. Para producir toda esta cantidad de objetos, los contenidos se centran en la enseñanza y aprendizaje de diferentes técnicas [...] (ACASO, 2009, p. 90).
\end{abstract}

Será que um jacaré feito igualmente por todas as crianças, com o mesmo material, seguindo um modelo preestabelecido, permite uma lembrança, um vínculo afetivo, uma memória positiva da visita ao museu? Se essas propostas práticas têm o objetivo de fazer as crianças levarem consigo uma recordação, uma lembrança do momento vivido no museu, então tais propostas são realmente compreensíveis, pelo fato de que "a memória é uma construção efêmera e transitória que pode necessitar de objetos para inscrever sua pertinência. Isto é ainda mais verdadeiro no caso das crianças pequenas que estão em processo de construção do seu pensamento [...]" (ABAD; CHAVEPEYER, 2014, p. 12). Mas, ressalta-se, é necessário repensá-las.

Com base em Abad e Chavepeyer (2014), encontramos outro caminho para pensar as oficinas centradas no fazer artístico. Trata-se do 'objeto memória', que

[...] permite prolongar a experiência, de carregar consigo um traço material [...]. Ele pode também estar investido do poder de invocar, "pedindo" aos pais que voltem ao museu para dar continuidade à experiência que fora 
iniciada com ele, objeto, ou permitindo uma primeira narração da experiência vivida. O objeto memória tem, portanto, a função de oferecer um apoio à memória através de um traço, um vestígio material (um pedaço de lã, um pedacinho de papel, uma imagem...) ou imaterial (um conto, um refrão musical...) [...]. Esse objeto memória é também um símbolo, na medida em que estabelece um vínculo entre duas identidades e permite prolongar a experiência até o cotidiano das crianças, seja em suas casas, seja na creche (ABAD; CHAVEPEYER, 2014, p. 13).

Ao olhar por essa perspectiva, o objeto memória distingue-se das práticas desenvolvidas nos trabalhos manuais tradicionais sistemáticos. Por outro lado, é importante investir em ações que acontecem no próprio espaço expositivo, por intermédio da interação e manipulação das obras que permitirem isso, ou a possibilidade de investir em uma ação que envolva a brincadeira, o corpo e a exploração dos sentidos no espaço expositivo que se visita.

Alguns autores dizem que muitas vezes esse tipo de ação, que ocorre nas oficinas, confunde-se com o que acontece na escola, porque há certa escolarização nos museus, e práticas que ocorrem na escola frequentemente são incorporadas no museu. Santos (1997, p. 28) ressalta, porém, que "a 'escolarização' do museu seria um equívoco, visto que este deveria procurar promover atividades baseadas em metodologias próprias - um 'fazer educativo-museológico'”. O fazer museológico deve ser baseado nas especificidades de cada público que visita o museu e, ainda, necessita acompanhar o pensamento e as transformações pós-modernas. Acaso (2008, p. 295) faz a seguinte consideração:

[...] el núcleo base de esta educación posmoderna consiste en alentar en el espectador el desarrollo de conocimiento propio en vez de introducirle conocimiento importado. La base de la tarea educativa radica en desarrollar una filosofía didáctica donde cada agente (en este caso, el museo) no solo planifique objetivos, sino que reflexione sobre qué quiere hacer mediante dicha tarea.

Nesse sentido, as práticas educativas que acontecem no museu precisam ser diferenciadas das escolares. Com base no estudo de Dornelles (2013), é possível pensar de uma forma diferente a educação museal desenvolvida na mediação cultural com as crianças pequenas, aproveitando o imaginário infantil, de modo a romper com a tradicional pergunta dos mediadores sobre o que as crianças veem na obra. Ao contrário, "poderia ser criado algo novo, a partir do que elas elencassem como significativo para o que estão sentindo, vendo, interagindo. [...] Viver com elas a experiência do espaço expositivo" (DORNELLES, 2013, p. 91). Com o mesmo 
pensamento, Leite aborda questões fundamentais que o museu necessita rever ao acolher as crianças pequenas, pois elas deveriam ter

\begin{abstract}
[...] livre acesso ao espaço museal (possibilidade de freqüência regular e circulação/acesso direto às coleções expostas nos museus); possibilidade de visualização (com objetos dispostos na altura de seus olhos) e, sempre que possível, manipulação (galerias interativas); facilidade na inteligibilidade das mensagens (com etiquetas múltiplas em linguagem não-escrita ou escrita direta e simples); chances de participação em propostas desafiadoras, lúdicas e criativas que levem em conta seus conhecimentos prévios e que estimulem sua imaginação e diferentes linguagens expressivas; possibilidade de constituir significação ao visto/vivido de forma aberta e autoral através da participação em/criação de narrativas, nas quais sua voz seja ouvida e respeitada [...] (LEITE, 2007, p. 152).
\end{abstract}

Esse encontro entre as crianças e a arte no museu, conforme aponta Leite (2013), poderia "gerar uma boa experiência envolvendo imaginação, curiosidade, sensações, descoberta, observação, estranhamento, reflexão, ludicidade, encantamento, criação, execução", ou seja, evidenciar as culturas infantis. Porém, é valido considerar que $\mathrm{o}$ ato de visitar o museu não se restringe ao momento vivenciado no museu. Essa ação deve ser parte de um planejamento que se inicia na própria unidade escolar e se possível em parceria com o museu. Tal apontamento sobre a 'colaboração entre museus e centros de educação infantil' é feito também no documento Manifesto: Museos de arte amigos de los niños pequenos. Nele se destaca que os museus poderiam apoiar os professores nesse processo acolhendo-os calorosamente. Assim, seria desfeita a ideia de que a arte é um campo reservado a certa elite. E ainda, "de los intercambios entre museos y profesionales de la primera infancia pueden surgir proyectos de colaboración gracias a las competencias de cada uno (...) y incluso prever pequeñas muestras o exposiciones pensadas para ellos." (FALLON; CHAVEPEYER, 2013, p. 14). E, por esse caminho, o museu pode propor visitas não só às unidades escolares, como também aos pais e seus filhos.

Essas questões validam a necessidade e a possibilidade de um trabalho em colaboração para se pensar as crianças pequenas no museu. Assim sendo, salientamos que vários autores destacam que o trabalho articulado entre escola e museu, para que seja uma experiência significativa para ambos, pode ser desenvolvido em três importantes momentos: o que acontece antes da visita, no espaço escolar; o que se desenvolve durante a visita, no espaço do museu; e o que 
continua na escola, depois da visita.

Salientamos que, para pensar esse trabalho no contexto da educação infantil, devem ser levadas em consideração as reflexões sobre os saberes necessários, apontadas neste texto, e é preciso considerar a importância de um planejamento compartilhado entre mediadores e educadores.

Para finalizar as reflexões, concluímos que, a partir do entendimento de um museu educativo, que olha para o público e permite sua participação ativa, reconhecer a presença da criança da educação infantil em seu espaço se torna necessário contanto que haja disponibilidade e investimento não apenas intelectual, mas também sensível daqueles que estão diretamente envolvidos nessa tarefa. Todavia ressaltamos que, para alcançar o patamar de um museu educativo que realmente age em prol da infância, é necessário construir tal caminho em pequenas ações, e uma das possibilidades é o trabalho interinstitucional em colaboração.

\section{SOLANGE DE FÁTIMA GABRE}

Doutora em Educação pela Universidade Federal do Rio Grande do Sul (UFRGS), com estágio na Universidad Complutense de Madrid, Espanha. Mestre em Patrimônio Cultural e Sociedade pela Universidade da Região de Joinville (UNIVILLE). Especialista em Museologia pela Escola de Música e Belas Artes do Paraná e em Educação Especial/Inclusão pela Universidade Federal do Paraná (UFPR). Atua na Secretaria Municipal da Educação de Curitiba (PR).

\section{REFERÊNCIAS}

ABAD, J. M.; CHAVEPEYER, I. Olhares cruzados. Museus, artes vivas e primeira infância: encontro internacional - Limoges 2014. Tradução de Ana Lúcia Silva Paranhos. (Não publicado).

ABAD, J. M.; VELASCO, A. R. G. El juego simbólico. Barcelona: Graó, 2011.

ACASO, M. El museo como plataforma de transformación de la pedagogía tóxica. Módelos educativos no tóxicos para una sociedad posmoderna. In: I CONGRESO INTERNACIONAL LOS MUSEOS EN LA EDUCACIÓN. La formación de los educadores. Actas... Madrid, 2008.

ACASO, M. La educación artística no son manualidades. Madrid: Catarata, 2009. 
ACASO, M. Perspectivas: situación actual de la educación en los museos de artes visuales. Madrid: Ariel Fundación Telefónica, 2011.

ALDEROQUI, S. Nuevas relaciones entre museos y escuelas. Madrid, 2015. (Comunicação oral). Disponível em: <https://www.youtube.com/watch?v=WZ5FzF0DSAo>. Acesso em: ago. 2015.

BARBOSA, A. M. Mediação cultural e social. In: BARBOSA, A. M.; COUTINHO, R. (Orgs.). Arte/Educação como mediação cultural e social. São Paulo: UNESP, 2009.

BENVENUTI, A. Museus e educação em museus - história, metodologias e projetos, com análise de caso: Museus de Arte Contemporânea de São Paulo, Niterói e Rio Grande do Sul. 2004. Dissertação (mestrado) - Instituto de Artes, Universidade Federal do Rio Grande do Sul, Porto Alegre.

BRASIL. Lei n. 9.394, 20 de dezembro de 1996. Estabelece as diretrizes e bases da educação nacional. Brasília, 1996.

BRASIL. Lei n. ${ }^{\circ} 11.094$, de 14 de janeiro de 2009. Institui o Estatuto de Museus e dá outras providências. Brasília, 2009.

CABRAL, M. Avaliação das ações educativas em museus brasileiros. 2006. Disponível em: <www.icom.org.br/avaliacao_acoes_educ_museus_bras.pdf.>. Acesso em: jan. 2013.

CAMNITZER, L. Introdução. In: BARREIRO, G. P.; CAMNITZER, L. (orgs.). Educação para a arte, arte para a educação. Porto Alegre: Fundação Bienal do Mercosul, 2009.

CAMNITZER, L. Entre pensamiento crítico y cinismo ético. Entrevista. Imagentexto, 2011. Disponível em: <http://imagen-texto.blogspot.com.br/2011/12/luis-camnitzerentre-pensamiento.html>. Acesso em: 25 nov. 2015.

CARVALHO, C. "Criança menorzinha... Ninguém merece!": políticas de infância em espaços culturais. In: ROCHA, E. A. C.; KRAMER, S. (orgs.). Educação infantil: enfoques em diálogo. Campinas: Papirus, 2013.

COCA, P. Proyectos educativos en contextos expositivos. Pulse, v. 32, p.177-199, 2009. Disponível em: <file:///C:/Users/cralcantara/Downloads/DialnetProyectosEducativosEnContextosExpositivos-3068554.pdf>.

COCA, P.; PÉRES, Á. M. Repensar las prácticas educativas em museos y centros de ensiñanza. Arte y Políticas de Identidad, v. 5, p. 13-26, dez. 2011.

COCA, P. El comisariado educativo como modelo de gestión de espacios expositivos en museos de arte contemporáneo. 2014. 72 f. Tese (doutorado) - Faculdade de Educación y Trabajo Social, Universidad de Valladolid, Valladolid.

CUNHA, S. R. V da (org.). As artes no universo infantil. Porto Alegre: Mediação, 2012. 
DAHLBERG, G.; MOSS, P.; PENCE, A. Qualidade na educação da primeira infância: perspectivas pós-modernas. Porto Alegre: Artmed, 2003.

DORNELLES, A. E. Crianças em espaços expositivos: abrimos a porta do gigante. 2013.110 f. Dissertação (mestrado) - Universidade Federal do Rio Grande do Sul, Porto Alegre.

EFLAND, A. D.; FREEDMAN, K.; STUHR, P. La educación en el arte posmoderno. Buenos Aires: Paidós, 2003.

FALLON, C.; CHAVEPEYER, I. Manifesto: museos de arte amigos de los niños pequeños. Bruxelas: Teatro de la Guimbarde y del FRAJE, 2013.

FUNDACIÓN MALBA. Luis Camnitzer sobre su obra El museo es una escuela. 2015. Disponível em: <http://www.malba.org.ar/luis-camnitzer-el-museo-es-una-escuela/>.

GABRE, S. de F. Para Habitar o Museu com o Público Infantil: uma proposta de formação colaborativa entre professoras da infância e profissionais do Museu Municipal de Arte de Curitiba. 2016. 235f. Tese (Doutorado). Universidade Federal do Rio Grande do Sul.

HUERTA, R. ¿Por qué se necesitan las escuelas y los museos? In: HUERTA, R. Maestros y museos: educar desde la invisibilidade. València: Universitat de València, 2010.

IBRAM - INSTITUTO BRASILEIRO DE MUSEUS. Documento preliminar do Programa Nacional de Educação Museal - PNEM. Disponível em: <http://pnem.museus.gov.br/documento-base/>. Acesso em: fev. 2014.

LEITE, M. I. Museus de arte: espaços de educação e cultura. In: LEITE, M. I.; OSTETTO, L. E. (orgs.) Museu, educação e cultura: encontro de crianças e professores com a arte. Campinas: Papirus, 2005.

LEITE, M. I. A dimensão educativa dos museus londrinos - o olhar estrangeiro. Relatório final de pesquisa de pós-doutorado. Roehampton University, 2007.

LEITE, M. I. Museu também é lugar para criança pequena! Museu Iberê Camargo, 2013. (Comunicação oral).

LIMA, J. D. de S. Trocando experiências: a aventura moderna revisitada na proposta de mediação da mostra Acácio Gil Borsói e os artistas Vicente do Rego Monteiro e João Câmara. In: BARBOSA, A. M.; COUTINHO, R. G. (orgs.). Arte/Educação como mediação cultural e social. São Paulo: UNESP, 2009.

MELO, J. Simpósio Arte na Pedagogia. Universidade Mackenzi, São Paulo, 2015. (Comunicação oral).

MÖRSCH, C. Educación crítica en museos y exposiciones en el contexto del "giro 
educativo" en el discurso comisarial: ambigüedades, contradicciones y alianzas. In: Memorias MDE11. Medellín, Colombia, 2011. Disponível em: <http://issuu.com/museodeantioquia/docs/mde11_ministerio_de_cultura_public>. Acesso em: 27 nov. 2015.

MÖRSCH, C. Contradecirse una Misma: la educación en museos y exposiciones como práctica crítica. In: CEVALLOS, A.; MACAROFF, A. (orgs.). Contradecirse una Misma: museos y mediación educativa crítica. Quito: Fundación Museos de la Ciudad, 2015.

SANTOS, M. de O. C. Lições das coisas (ou canteiro de obras) através de uma metodologia baseada na educação patrimonial. Dissertação (Mestrado) - Pontifícia Universidade Católica do Rio de Janeiro, Rio de Janeiro, 1997.

SARMENTO, M. J. As culturas da infância nas encruzilhadas da segunda modernidade. In: SARMENTO, M. J.; CERISARA, A. B. Crianças e miúdos: perspectivas sociopedagógicas da infância e educação. Porto: Asa, 2004.

SARMENTO, M. J. A Sociologia da infância e a sociedade contemporânea: desafios conceituais e praxeológicos. In: ENS, R. T; GARANHANI, M. (orgs.). Sociologia da infância e a formação de professores. Curitiba: Champagnat, 2013.

SILVA, F. B. da. Economia e política cultural - acesso, emprego e financiamento. Brasília: IPEA, 2007. v. 1. 308 p.

SILVA, F. B. da et al. Encontros com o futuro: prospecções do campo museal brasileiro no início do século XXI. Brasília: IBRAM/IPEA, 2014. 142 p. (Coleção Museu, economia e sustentabilidade, 1).

TARDIF, M. Saberes docentes e formação profissional. Petrópolis: Vozes, 2002. 